\title{
On the aesthetic education in College Physical Education
}

\author{
Xiang Zhang \\ Weihai vocational college, Shandong 264200, China
}

\section{sasla@163.com}

\begin{abstract}
This paper first introduces the aesthetic teaching in college physical education, and further analyzes the existing problems of aesthetic education into college sports teaching, at the end of this paper, the author combined with the current problems, further puts forward the method of penetrating strategy the aesthetic education in Physical Education in Colleges and universities.
\end{abstract}

Keywords Colleges and universities physical education infiltration

\section{The role of aesthetic education in College Physical Education}

Aesthetic teaching is an essential component of any person. In the teaching of physical education into the basic idea of aesthetics that long-standing, Chinese scholars have also made considerable achievements in the research, some scholars believe that the aesthetic education and moral education, physical education has equal status, it is important for the growth and development of the individual to. Aesthetic and sports are closely related to the two. The aesthetic education into the teaching of physical education cannot only effectively improve the quality of students, but also can help students form a more sound personality. In the teaching of physical education for students to bring a basic sense of aesthetics, to promote students in the exercise of the correct aesthetic concept. High school sports teaching the main emphasis is to enhance the physical quality of the students, carry out the premise of this activity is to enhance the students' interest in sports, if the lack of necessary sports interest, even if we are forced to participate, is unable to realize the sports learning in junior high school, nature 
will not have too strong interest. Therefore, in order to further stimulate the students"s interest in sports, a lot of physical education teachers will integrate some elements of the game in physical education, in order to stimulate students' interest in sports learning. Into the basic aesthetic concept in the sports teaching, the teacher's explanation is no longer about the pure theory, but through subtle rhythm to influence students, improve students' aesthetic ability, in a subtle process, the aesthetic ideas of the influence of students, promote students to enjoy sports.[1]

\section{College sports teaching penetration of aesthetic education problems}

\section{1 lack of adequate attention}

A variety of problems existing in college sports teaching in the moment, the most important question is that many teachers did not recognize the importance of aesthetic education, influenced by the traditional hard education teachers, the requirements for teaching still stays in the exam, that students get good grades, can be the way. Although physical education teaching in colleges and universities in recent years, in the content of education to achieve a certain change, but compared with the actual needs, there are still many problems. For example, college sports curriculum, lack of hierarchy, no curriculum design, students in school during the learning of sports is still single, course each semester has a repetition of the fact is too high, the opinions and ideas are very narrow, education for the students are not a cure.

\section{2 ideas behind}

Some college sports teachers lack the idea of advancing with the times, with the continuous progress of the era, educators should with their educational ideas, but the current college PE teachers most ideas are very backward, not follow the trend of the times, there is a significant lag. In the evaluation of physical education in the past, teachers tend to physical examinations, finally the students mainly in the evaluation process, pay no attention to the students' interest in training in the course of physical education efforts and movement, so that the sports teaching has become the form of "exam oriented teaching physical education teachers" this one-sided evaluation method in a certain extent. Not only to a certain extent on the students' interest in sports, but also dealt a blow to the students of the physical education curriculum learning enthusiasm, students can not lead to the correct view of sports curriculum, thus to some extent hindered the conduct of physical education.[2]

\section{3 teachers lack of professional quality}

Some College PE teachers' professional quality is not high, in the teaching activity, the cognitive level of PE teachers is low, coupled with the understanding of aesthetic education has obvious limitations, so in the teaching process it is difficult to achieve good results. This is likewise a major obstacle for students to accept aesthetic knowledge. At present, physical education teaching in colleges and universities is lack of teachers with rich experience, which leads to the back of the goal of physical education in colleges and universities. 


\section{The infiltration of aesthetic education in college sports teaching strategy}

3.1 integrate formal beauty and language beauty

In the actual teaching, teachers explain as well as knowledge is of great importance, so teachers need to constantly improve their own knowledge, in the process of teaching, to inspire students with the standard language and behavior. In the classroom, the teacher should respect the student's interest, because the interest is the premise of the study, only the students have full interest, they are willing to participate in classroom learning. Some teachers, frequent mistakes in the expression of thought, it is difficult to effectively grasp the essentials of teaching, make students lose interest in learning. With the new language to stimulate students' interest, and actively guide students to participate in the classroom, for students to create a good learning atmosphere, more conducive to enhance the effectiveness of student learning. In the teaching of physical education, to fully display the beauty of the form of the human body, so that students to perceive the beauty, and thus to achieve a subtle role in their thinking, to stimulate students' confidence in the exercise of sports.[3]

\section{2 integration of teaching objectives}

Physical education teachers should have advanced education thoughts and lofty spirit, give ample play to the ability of teachers in teaching and working, achieve better teaching objectives. The teacher should let the student strengthen the request to oneself, cannot easily reduce the standard and difficult. As a teacher, the teacher's words and deeds always affects the personality of students, teachers should improve themselves through the sentiment to motivate students more motivated, encourage students to pursue the ideal of beauty, to enable students to develop the spirit of giving them refuse to be cowed or submit, a more positive outlook on life and values. For some sports, students should hold the aesthetic mentality of good to see, not only in a narrow vision to judge and the pros and cons of competitions, athletes, analysis with a more meaningful perspective, and can achieve the effect of a sound personality. Physical education teachers in the process of education, do a good job in the role of physical education teachers will affect the behavior of college students, college students can develop good habits, to a large extent depends on the teachers themselves. Therefore, teachers should take full advantage of classroom time, for students to carry out serious and responsible guidance, as far as possible to regulate the exercise behavior of College students. In the process of teaching, teachers should ask students to seriously look at the demonstration, to understand the action essentials, independently complete the relevant action specified by the teacher.

\section{3 beautify the teaching environment}

In sports teaching, one of the most important factors is to have a good venue and qualified teaching equipment, sports teaching should focus on the teaching content of ingenious ideas, create a good scene, the sensory system can effectively stimulate students, impress the students deeply. Therefore, physical education teachers in the class, to effectively and effectively according to the contents of the lectures to arrange the venue, choose effective equipment. Clean, beautiful venues and equipment, can give students a superb, fresh feeling, can 
effectively stimulate students' interest in sports. In such an environment, students can consciously participate in the setting of the teachers, and with the best learning state to learn.

\section{4 optimization of teaching methods}

Physical education teachers in the specific teaching activities, students can actively understand the characteristics, such as gender, age and so on to choose different teaching methods. In addition, we should pay heed to the diversity of teaching, and effectively cultivate students' aesthetic and creative ability. Physical education teachers in the teaching of physical education infiltration of some aesthetic factors, can be completed through demonstration. For example, physical education teachers should do as much as possible generous, decent, and has good coordination, so that students from a good image of the mind. In order, to help the students to feel and appreciate the beauty, teachers can stimulate students' learning motivation and cultivate students' interest in learning. Teachers explain to students in action, but also possible to do simple and easy to understand, let the classroom become lively and interesting, so that it can better inspire students, to show students and sports is closely linked to the sense of beauty.

Teachers in the form of teaching organization, the team can be converted to square, round, curved and straight lines, etc., from the visual angle to further arouse the students' feelings of beauty. In the process of training, the teacher can choose some more cheerful music accompaniment, so that students can enjoy showing their rhythm and sense of rhythm. When teaching, teachers can choose a proper miracle, learning content and competition in the form of combination, which cannot only effectively mobilize the classroom atmosphere, but also can make students by observing others to appreciate the charm of sports action. To encourage students to feel the beauty of sports through their own experience, so that the aesthetic process from content to form an effective unity.

\section{5 rich teaching content}

Somatic education can help students improve their ability to exercise by physical exercise. In the past, the teaching method was only to instill physical knowledge to the students, and the whole class is the lack of interest, which leads to the students"s enthusiasm for physical education, thus affecting the quality of physical education. Teachers should consider the students the difference, according to the individual needs of students and the characteristics of the system, adopts different teaching methods and levels, to develop effective evaluation strategies to promote students' personalized development. Sports teaching is not only to enhance their physique, promote students to improve sports skills, but also to cultivate students' aesthetic ability to do some sports, including the form and action of the United States, so that the students' physical exercise and aesthetic ability to be further combined with the. Therefore, physical education should not only physical training, but also should arrange some has flexibility and coordination activities, enhance students' reaction speed, strain capacity, truly realize the unity of tactics and wisdom, some teachers can even choose some Tai Chi class project, let students know more about the beauty of creation, beauty. In addition, teachers should also pay attention to the moral education of the students, 
let students understand the wonderful in sports, what kind of behavior is really good, what kind of behavior is evil, all these need to implement sports teaching.

\section{6 regulate their own instruments}

PE teachers should always pay attention to their appearance and dress, beauty instrument can give students more energetic feeling, elegant, neat dress not only can cultivate students' emotions, but also can stimulate students' pursuit for the beauty. To promote students' understanding and appreciation of beauty, which makes students' aesthetic ability to be enhanced. The students' aesthetic object is the most direct teachers. Teachers will affect the students every word and action of the senses. Teachers should understand the words and deeds, skilled at giving systematic guidance to improve students' aesthetic ability, to a certain extent. Physical education teachers, has a young, healthy attitude, affect students' attitude towards life, use civilized language, sincere attitude and neat appearance, establish a life model for students, realize the unified image and teaching.

\section{Conclusion}

Generally speaking, physical education and reputation education are closely linked, from the beginning to the end of physical education throughout the education of the United States. Physical education and aesthetic education are inseparable links. The two played a role in promoting each other, complement each other. It is a key way to cultivate students' comprehensive quality in the teaching of physical education. Sports can make people healthy and strong, and aesthetic education can improve a person's aesthetic style, from the point of view, will be fully incorporated into the aesthetic education in physical education is very necessary. Educators are required to sum up the corresponding methods and methods to optimize the educational achievements, to achieve the quality of physical education in Colleges and universities.

\section{References}

[1] Swanger D, Physical Education, Aesthetic Education and the Necessities of Democracy. Art Education, 44(2),pp:46,2015.

[2]Hadzigeorgiou Y, Schulz R, Romanticism and Romantic Science: Their Contribution to Science Education. Science \& Education, 23(10),pp:19632006,2014.

[3]Sato R, Takeshi K,A Consideration of Music Curriculum in American Education : From the Viewpoint of Aesthetic Knowing. Ecoscience, 48(4),pp:560-561,2005. 